\title{
Digital Morphometrics
}

\section{A New Upper Airway Phenotyping Paradigm in OSA}

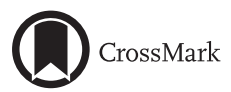

Richard J. Schwab, MD; Sarah E. Leinwand, MPH; Cary B. Bearn, MS; Greg Maislin, MS; Ramya Bhat Rao, DMD;

Adithya Nagaraja, BA; Stephen Wang, BS; and Brendan T. Keenan, MS

BACKGROUND: OSA is associated with changes in pharyngeal anatomy. The goal of this study was to objectively and reproducibly quantify pharyngeal anatomy by using digital morphometrics based on a laser ruler and to assess differences between subjects with OSA and control subjects and associations with the apnea-hypopnea index (AHI). To the best of our knowledge, this study is the first to use digital morphometrics to quantify intraoral risk factors for OSA.

METHODS: Digital photographs were obtained by using an intraoral laser ruler and digital camera in 318 control subjects (mean AHI, 4.2 events/hour) and 542 subjects with OSA (mean AHI, 39.2 events/hour).

RESULTS: The digital morphometric paradigm was validated and reproducible over time and camera distances. A larger modified Mallampati score and having a nonvisible airway were associated with a higher AHI, both unadjusted $(P<.001)$ and controlling for age, sex, race, and BMI $(P=.015$ and $P=.018$, respectively). Measures of tongue size were larger in subjects with OSA vs control subjects in unadjusted models and controlling for age, sex, and race but nonsignificant controlling for BMI; similar results were observed with AHI severity. Multivariate regression suggests photography-based variables capture independent associations with OSA.

CONCLUSIONS: Measures of tongue size, airway visibility, and Mallampati scores were associated with increased OSA risk and severity. This study shows that digital morphometrics is an accurate, high-throughput, and noninvasive technique to identify anatomic OSA risk factors. Morphometrics may also provide a more reproducible and standardized measurement of the Mallampati score. Digital morphometrics represent an efficient and cost-effective method of examining intraoral crowding and tongue size when examining large populations, genetics, or screening for OSA.

CHEST 2017; 152(2):330-342

KEY WORDS: digital morphometrics; modified Mallampati; OSA; tongue; upper airway

ABBREVIATION: AHI = apnea-hypopnea index

AfFILIATIONS: From the Division of Sleep Medicine (Dr Schwab and Mr Maislin) and the Center for Sleep \& Circadian Neurobiology (Drs Schwab and Rao, Ms Leinwand, and Messers Bearn, Maislin, Wang, and Keenan), Philadelphia, PA; and the University of Pennsylvania (Ms Nagaraja), Philadelphia, PA.

FUNDING/SUPPORT: The investigation was supported by two National Institutes of Health [Grants HL089447 ("Obesity and OSA: Understanding the Importance of Tongue Fat \& Metabolic Function") and HL 094307 ("Understanding the Relationship Between Obesity and Tongue Fat")].
CORRESPONDENCE TO: Richard J. Schwab, MD, Department of Medicine, Division of Sleep Medicine, Pulmonary, Allergy and Critical Care Division, Penn Sleep Center, University of Pennsylvania Medical Center, 3624 Market St, Ste 205, Philadelphia, PA 19104; e-mail: rschwab@mail.med.upenn.edu

Copyright $@ 2017$ American College of Chest Physicians. Published by Elsevier Inc. All rights reserved.

DOI: http://dx.doi.org/10.1016/j.chest.2017.05.005 


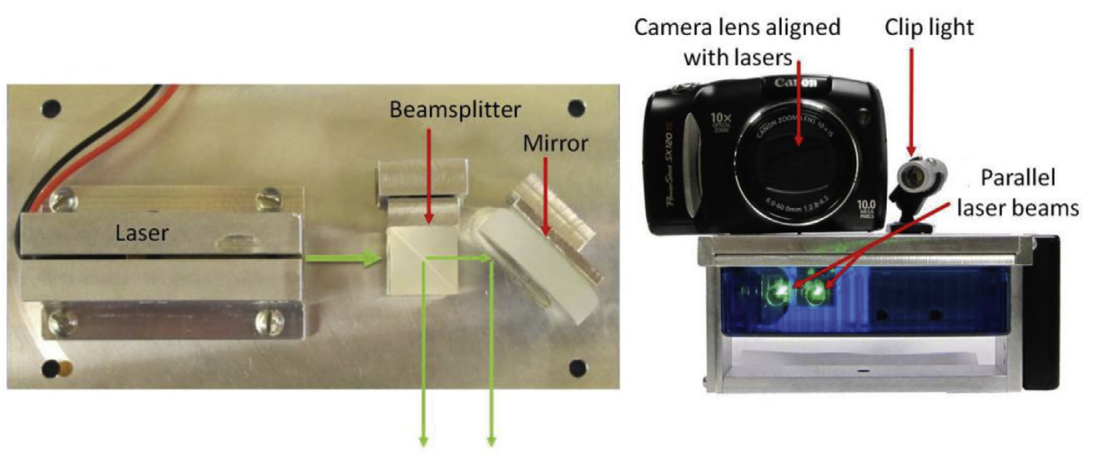

Figure 1 - Laser ruler device. Left shows the interior mechanics of the laser ruler device with the beam splitter and mirror positioned to project two parallel laser beams. Right shows the laser ruler with the camera and clip light attached to the device.

The prevalence of OSA in the adult population is estimated to be approximately $34 \%$ for men and $17 \%$ for women, with $13 \%$ and $6 \%$, respectively, having moderate-to-severe OSA (apnea-hypopnea index $[\mathrm{AHI}] \geq 15)^{1,2}$ Increased OSA risk is associated with aging, obesity, and male sex. ${ }^{3,4}$ Although obesity is the most important risk factor, ${ }^{3-7}$ studies show that craniofacial abnormalities (ie, reduction in mandibular size) and upper airway soft tissue enlargement increase the prevalence and severity of OSA..$^{8-11}$ Larger tongue, lateral pharyngeal walls, tonsils, soft palate, and total pharyngeal soft tissue volumes, as well as a shorter maxilla, smaller mandibular enclosure, and greater mandibular retroposition, have all been shown to increase OSA risk when measured according to MR and CT images. ${ }^{9,10,12-15}$ Although these studies provide important insights, such imaging techniques can be time-consuming, expensive, and expose subjects to varying levels of radiation. ${ }^{8-10,12-14}$

Alternative phenotyping methods have primarily relied on qualitative studies of tonsil size, Mallampati score, and pharyngeal narrowing. ${ }^{16-19}$ The Mallampati score, originally described with the tongue extended, is a measure of pharyngeal crowding used to predict difficulty in intubation. ${ }^{20}$ Modified Mallampati is scored with the tongue in the mouth and used to measure pharyngeal crowding while better representing the tongue position during sleep. ${ }^{18,20}$ In an attempt to obtain more quantitative morphometric measurements, calipers have been used to measure the oral cavity and craniofacial dimensions. ${ }^{21,22}$ Calipers allow for quantification; however, there are few data on reproducibility, and the process is cumbersome and unpleasant.

Lee et $\mathrm{al}^{23}$ described a novel photographic technique to quantify craniofacial measures without calipers. A washer of known size was affixed to the subject's face and used to calibrate measures taken from digital photographs. Using this technique, mandibular length was found to be shorter in subjects with OSA than in control subjects. In the present study, we extended this approach to quantify intraoral measures related to soft tissue structures. However, because a washer cannot be placed within the oral cavity, we used a projected laser ruler for calibration (Fig 1). The laser ruler, consisting of two parallel beams a known distance apart, was used to convert photographic measurements from pixels to centimeters, allowing for objective quantification of intraoral structure sizes.

The primary goal of the present study was to objectively and reproducibly quantify pharyngeal structures by using digital morphometrics based on a laser ruler and to assess differences between subjects with OSA and control subjects and associations with AHI. We hypothesized that larger intraoral structures measured via photography would be associated with higher $\mathrm{AHI}$ and increased risk of OSA. Furthermore, we hypothesized that there would be decreased visibility of the pharyngeal airway and a higher modified Mallampati score in subjects with OSA compared with control subjects.

Portions of this investigation have been presented as abstracts. $^{24-27}$

\section{Subjects and Methods}

Additional details are presented in e-Appendix 1 and e-Tables 1-4.

\section{Study Population}

Subjects with OSA were defined as having an AHI $\geq 10$ events/hour and control subjects as having an $\mathrm{AHI}<10$, as in previous studies. $^{7,28}$ Tables 1 and 2 provide descriptions of the photographs and measurements.

\section{Overnight Polysomnography}

Subjects underwent either an overnight in-laboratory polysomnography $(\mathrm{n}=787[91.5 \%])$ or a home study with an Embletta Gold portable monitor (Natus Medical Incorporated) $(n=73$ [8.5\%]). Studies were scored 
TABLE 1 ] Descriptions of Primary Facial Photographs (Intraoral and Soft Tissue) Analyzed

\begin{tabular}{|c|c|c|}
\hline Photograph & Description & Measures \\
\hline Photograph P1 & $\begin{array}{l}\text { Picture taken from the front, with subject's mouth open } \\
\text { maximally, tongue within the mouth and no phonation }\end{array}$ & $\begin{array}{l}\text { Modified Mallampati score; lateral mouth } \\
\text { width; vertical mouth height; mouth } \\
\text { area; tongue width; airway visibility }\end{array}$ \\
\hline Photograph P2 & $\begin{array}{l}\text { Picture taken from the front, with subject's mouth open } \\
\text { maximally and tongue extended out of the mouth and } \\
\text { downward maximally }\end{array}$ & $\begin{array}{l}\text { Standard Mallampati score; lateral } \\
\text { mouth width; tongue length; tongue } \\
\text { width; tongue area }\end{array}$ \\
\hline Photograph P3 & $\begin{array}{l}\text { Picture taken from the side (profile), with subject's mouth } \\
\text { open maximally and tongue extended out of the mouth } \\
\text { and downward maximally }\end{array}$ & $\begin{array}{l}\text { Tongue length; tongue area; tongue } \\
\text { thickness; tongue curvature }\end{array}$ \\
\hline Photograph P4 & $\begin{array}{l}\text { Picture taken from the front, with subject's mouth open } \\
\text { maximally, tongue depressed in the mouth and no phonation }\end{array}$ & $\begin{array}{l}\text { Airway width; uvula length, width and } \\
\text { area at the airway }\end{array}$ \\
\hline
\end{tabular}

TABLE 2 ] Descriptions of Intraoral and Craniofacial Measures Obtained via Photography

\begin{tabular}{|c|c|c|c|}
\hline Variable & Unit & $\begin{array}{l}\text { Photograph } \\
\text { (P) }\end{array}$ & Description \\
\hline \multicolumn{4}{|l|}{ Quantitative measures } \\
\hline Lateral mouth width & $\mathrm{cm}$ & $\mathrm{P} 1, \mathrm{P} 2$ & $\begin{array}{l}\text { The lateral width of the opening of the intraoral cavity, measured as a } \\
\text { horizontal line drawn between the right and left corners of the mouth }\end{array}$ \\
\hline $\begin{array}{l}\text { Vertical mouth } \\
\text { height }\end{array}$ & $\mathrm{cm}$ & $\mathrm{P} 1$ & $\begin{array}{l}\text { The maximal vertical height of the opening of the intraoral cavity, } \\
\text { measured as a vertical line drawn from the inner edge of the upper lip } \\
\text { to the inner edge of the lower lip }\end{array}$ \\
\hline Mouth area & $\mathrm{cm}^{2}$ & $\mathrm{P} 1$ & $\begin{array}{l}\text { The total area of the opening of the intraoral cavity, measured as a polygon } \\
\text { bounded by the inner edges of the lips and the corners of the mouth }\end{array}$ \\
\hline Tongue width & $\mathrm{cm}$ & P1, P2 & $\begin{array}{l}\text { The maximum width of the extended tongue, measured as the widest } \\
\text { horizontal line drawn across the tongue }\end{array}$ \\
\hline Tongue length & $\mathrm{cm}$ & $\mathrm{P} 2$ & $\begin{array}{l}\text { The length of the extended tongue in the median, measured as the } \\
\text { longest vertical line drawn down the center of the visible tongue }\end{array}$ \\
\hline Tongue area & $\mathrm{cm}^{2}$ & $\mathrm{P} 2, \mathrm{P} 3$ & $\begin{array}{l}\text { The visible surface area of the extended tongue, measured as a polygon } \\
\text { bounded by the visible edges of the tongue }\end{array}$ \\
\hline Tongue length & $\mathrm{cm}$ & P3 & $\begin{array}{l}\text { The length of the extended tongue, measured as a straight line between } \\
\text { the junction of the superior edge of the tongue and the upper lip to the } \\
\text { tip of the tongue, as seen from the profile }\end{array}$ \\
\hline Tongue thickness & $\mathrm{cm}$ & P3 & $\begin{array}{l}\text { The thickness of the extended tongue, measured as a straight line drawn } \\
\text { perpendicular to the tongue through the thickest portion of the tongue } \\
\text { completely visible beyond the intraoral cavity }\end{array}$ \\
\hline Tongue curvature & $\mathrm{cm}$ & P3 & $\begin{array}{l}\text { The length of the superior surface curve of the tongue, measured as a } \\
\text { curved line drawn from the junction of the tongue and the upper lip to } \\
\text { the tip of the tongue, as seen from the profile image }\end{array}$ \\
\hline Uvula length & $\mathrm{cm}$ & P4 & $\begin{array}{l}\text { The medial vertical length of the uvula, measured as a vertical line drawn } \\
\text { from the measured uvula width at the junction of the uvula and airway } \\
\text { to the tip of the uvula }\end{array}$ \\
\hline Uvula width & $\mathrm{cm}$ & P4 & $\begin{array}{l}\text { The maximum horizontal width of the uvula, measured as a horizontal line } \\
\text { drawn across the uvula at the junction of the uvula and upper airway }\end{array}$ \\
\hline Uvula area & $\mathrm{cm}^{2}$ & P4 & $\begin{array}{l}\text { The visible surface area of the uvula that hangs in the upper airway, } \\
\text { drawn as a polygon following the edges of the uvula and connecting } \\
\text { with a straight line across the uvula }\end{array}$ \\
\hline \multicolumn{4}{|l|}{ Categorical measures } \\
\hline $\begin{array}{l}\text { Modified Mallampati } \\
\text { score }\end{array}$ & $1-4$ & $\mathrm{P} 1$ & $\begin{array}{l}\text { Scoring of visibility of structures in the upper airway in photographs with } \\
\text { the tongue in the mouth }\end{array}$ \\
\hline $\begin{array}{l}\text { Standard Mallampati } \\
\text { score }\end{array}$ & $0-4$ & $\mathrm{P} 2$ & $\begin{array}{l}\text { Scoring of visibility of structures in the upper airway in photographs with } \\
\text { the tongue extended }\end{array}$ \\
\hline
\end{tabular}


TABLE 2 ] (Continued)

\begin{tabular}{|c|c|c|c|}
\hline Variable & Unit & $\begin{array}{l}\text { Photograph } \\
\qquad(P)\end{array}$ & Description \\
\hline $\begin{array}{l}\text { Pharyngeal airway } \\
\text { visibility }\end{array}$ & $0-1$ & $\mathrm{P} 1$ & $\begin{array}{l}\text { Dichotomous scoring of visibility of airway in photographs with the } \\
\text { tongue in the mouth }\end{array}$ \\
\hline $\begin{array}{l}\text { Presence of tongue } \\
\text { ridging }\end{array}$ & $0-1$ & $\mathrm{P} 1, \mathrm{P} 2, \mathrm{P} 4$ & $\begin{array}{l}\text { Dichotomous scoring of evidence of tongue ridging on frontal intraoral } \\
\text { photographs }\end{array}$ \\
\hline $\begin{array}{l}\text { Tonsil hypertrophy } \\
\text { grade }\end{array}$ & $0-4$ & $\mathrm{P} 1, \mathrm{P} 2, \mathrm{P} 4$ & $\begin{array}{l}\text { Grading of visible tonsil size based on encroachment of tonsils on } \\
\text { palatopharyngeal arches and upper airway }\end{array}$ \\
\hline $\begin{array}{l}\text { Pharyngeal } \\
\text { narrowing grade }\end{array}$ & $1-4$ & $\mathrm{P} 1, \mathrm{P} 2, \mathrm{P} 4$ & $\begin{array}{l}\text { Grading of pharyngeal narrowing based on intersection of } \\
\text { palatopharyngeal arches and tongue width }\end{array}$ \\
\hline
\end{tabular}
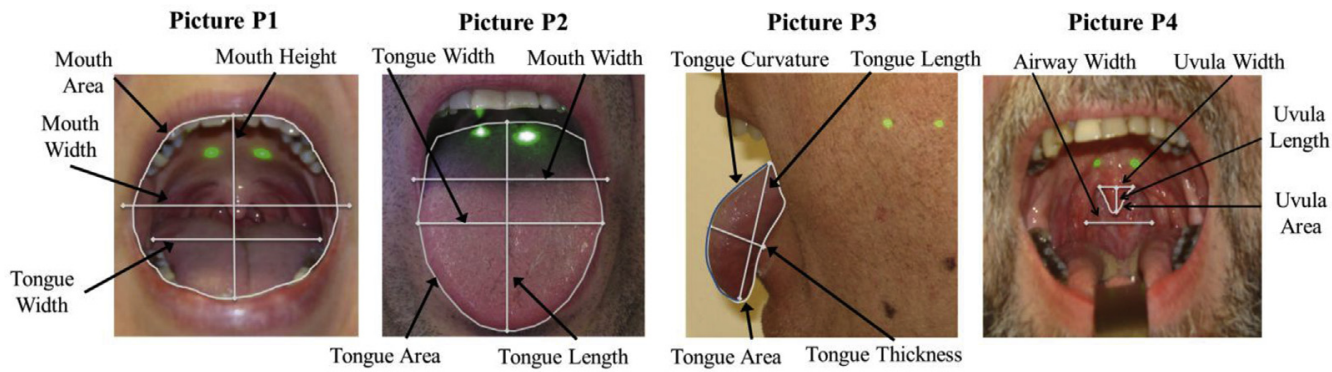

Figure 2 - Intraoral photographs with indicated measurements. The four photographs used to obtain measurements of intraoral structures are shown, with indicated measurements. The tongue within the mouth photograph (P1) shows the mouth width, height, and area and tongue width. The tongue-extended photograph (P2) shows the tongue width, length, and area as well as mouth width. The profile tongue-extended photograph (P3) shows tongue length, curvature (in blue), thickness, and area. The tongue-depressed photograph (P4) shows the uvula width, length, and area at the soft palate and airway width.
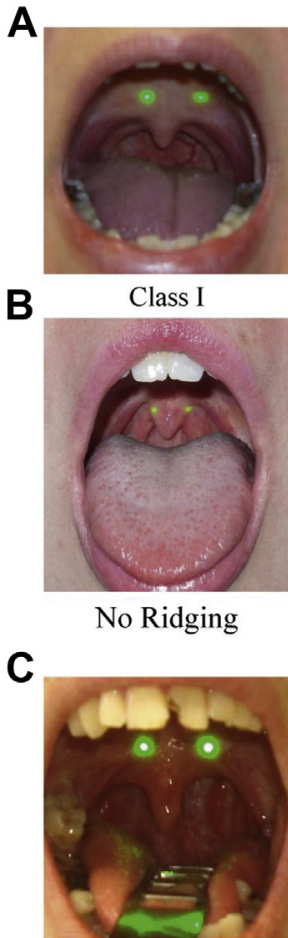

Grade 1

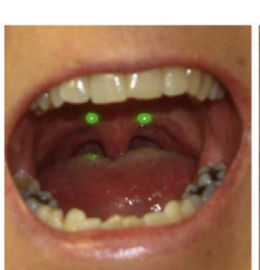

Class II

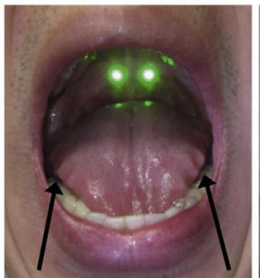

Evidence of Ridging

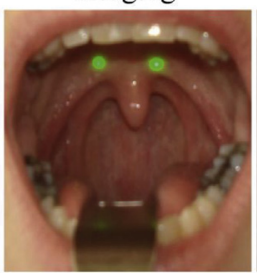

Grade 2

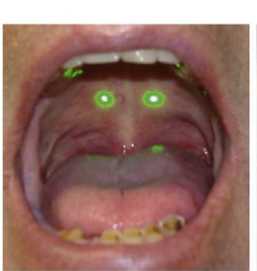

Class III

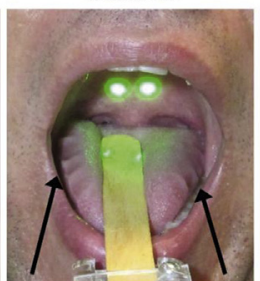

Evidence of Ridging

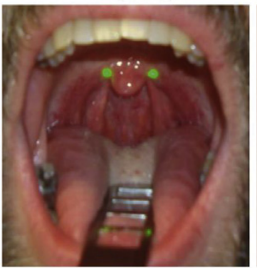

Grade 3

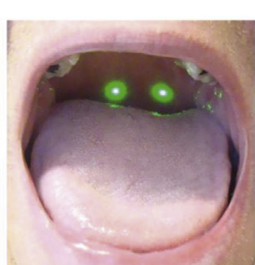

Class IV

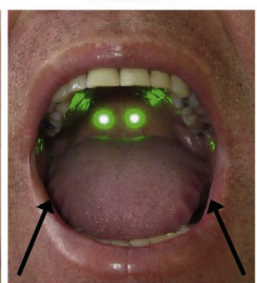

Evidence of Ridging

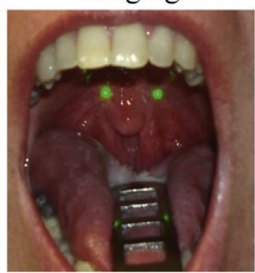

Grade 4

Figure $3-A-C$, Examples of the categorical photographic variables. (A) Modified Mallampati score: Representative examples of each modified Mallampati class obtained from photograph P1 are shown. Class I indicates full visibility of the uvula and tonsillar fossa. Class II indicates visibility of the upper portion of the uvula and partial visibility of the airway. Class III indicates visibility of the hard palate and base of the uvula. Class IV indicates visibility of the hard palate and no visibility of the soft palate. In addition to modified Mallampati scores, we derived a measure of airway visibility using these photographs; the airway is visible in Class I and Class II, but it is not in Class III and Class IV. (B) Tongue ridging. Representative examples of the absence of ridging and evidence of ridging (black arrows) are shown, from photograph $P 1, P 2$, or P4. If evidence of tongue ridging is visible in any frontal intraoral photo, subjects are then graded for presence of tongue ridging. (C) Pharyngeal narrowing. Representative examples of each grade of pharyngeal narrowing are shown, from photograph P1, P2, or P4. Grades are based on the location of the intersection between the palatopharyngeal arch and the tongue, relative to tongue width. Grade 1 indicates that the arch intersects at the edge of the tongue. Grades 2, 3, and 4 indicate that the palatopharyngeal arch intersects at $25 \%, 50 \%$, and $75 \%$ or more of the tongue width, respectively. 
by a trained sleep technologist and reviewed by certified sleep physicians according to methods of the American Academy of Sleep Medicine. ${ }^{29}$

\section{Laser Ruler}

Digital photographs were obtained by using a digital camera and intraoral laser ruler, composed of a right angle beam splitter and mirror aligned such that two parallel beams project forward a known distance apart (Fig 1). A camera was attached to the laser ruler to allow for digital photographs to capture the projected laser beams adjacent to measures of interest. The distance between the lasers ( 1.0 or $1.5 \mathrm{~cm}$ depending on the device) was used to calculate quantitative measures from the photograph.

\section{Morphometric Photographs}

For each photograph, subjects were seated with their head in a neutral position and line of sight parallel to the floor. ${ }^{29}$ The camera and laser ruler were placed between 35 and $50 \mathrm{~cm}$ from the subject. Subjects were instructed to open their mouths maximally for 4 intraoral photographs (Table 1) in the frontal or profile position (Fig 2): tongue in the mouth without phonation (frontal photograph), tongue extended (frontal photograph), tongue extended (profile photograph), and tongue depressed without phonation (frontal photograph). We also obtained categorical measures of pharyngeal airway visibility, modified and standard Mallampati scores, tongue ridging, tonsil hypertrophy grade, and pharyngeal narrowing grade (Fig 3).

\section{Statistical Methods}

Methods, sample size and power, and Hochberg multiple comparisons correction are given in e-Appendix $1 .{ }^{30,31}$

\section{Results}

\section{Validation and Reproducibility}

Details on validation and reproducibility are given in e-Appendix 1.

\section{Measurement Visibility}

We assessed our ability to measure the different structures overall and between subjects with OSA and control subjects (e-Table 4). Due to study design (adding new photographs and measurement variables to the paradigm), the number of subjects with OSA and control subjects with available data varied. Measurements capturing the size of the mouth and tongue were obtained in at least $89 \%$ of photographs (range, 89.2\%-99.0\%). Tongue width with the tongue in the mouth was obtained in a slightly lower proportion of subjects with OSA than in control

TABLE 3 ] Descriptive Statistics of Demographic Characteristics and Photographic Measures

\begin{tabular}{|c|c|c|c|c|c|c|c|}
\hline \multirow[b]{2}{*}{ Measure } & \multicolumn{2}{|c|}{ All Patients } & \multicolumn{2}{|c|}{$\begin{array}{l}\text { Control Subjects } \\
\quad(\text { AHI }<10)\end{array}$} & \multicolumn{2}{|c|}{$\begin{array}{l}\text { Subjects With OSA } \\
\quad(A H I \geq 10)\end{array}$} & \multirow[b]{2}{*}{$P$} \\
\hline & No. & Estimate & No. & Estimate & No. & Estimate & \\
\hline Age & 860 & $47.4 \pm 13.7$ & 318 & $42.7 \pm 13.9$ & 542 & $50.2 \pm 12.8$ & $<.0001$ \\
\hline BMI & 860 & $36.1 \pm 9.9$ & 318 & $32.1 \pm 8.6$ & 542 & $38.5 \pm 9.8$ & $<.0001$ \\
\hline Sex & & & & & & & .021 \\
\hline Male & 412 & $47.9 \%$ & 136 & $42.8 \%$ & 276 & $50.9 \%$ & \\
\hline Female & 448 & $52.1 \%$ & 182 & $57.2 \%$ & 266 & $49.1 \%$ & \\
\hline Race & & & & & & & $<.001$ \\
\hline White & 405 & $47.7 \%$ & 159 & $50.6 \%$ & 246 & $45.9 \%$ & \\
\hline African American & 387 & $45.5 \%$ & 122 & $38.9 \%$ & 265 & $49.4 \%$ & \\
\hline Other & 58 & $6.8 \%$ & 33 & $10.5 \%$ & 25 & $4.7 \%$ & \\
\hline $\mathrm{AHI}$ & 860 & $26.2 \pm 28.9$ & 318 & $4.2 \pm 2.8$ & 542 & $39.2 \pm 29.4$ & $<.0001$ \\
\hline $\ln (\mathrm{AHI}+1)$ & 860 & $2.72 \pm 1.17$ & 318 & $1.46 \pm 0.66$ & 542 & $3.46 \pm 0.67$ & $<.0001$ \\
\hline Modified Mallampati score, P1 & & & & & & & .018 \\
\hline Class I & 35 & $4.5 \%$ & 20 & $7.1 \%$ & 15 & $3.0 \%$ & \\
\hline Class II & 79 & $10.1 \%$ & 34 & $12.1 \%$ & 45 & $9.0 \%$ & \\
\hline Class III & 127 & $16.3 \%$ & 47 & $16.7 \%$ & 80 & $16.1 \%$ & \\
\hline Class IV & 538 & $69.1 \%$ & 180 & $64.1 \%$ & 358 & $71.9 \%$ & \\
\hline Airway visibility, P1 & & & & & & & .007 \\
\hline Visible & 114 & $14.6 \%$ & 54 & $19.2 \%$ & 60 & $12.0 \%$ & \\
\hline Not visible & 665 & $85.4 \%$ & 227 & $80.8 \%$ & 438 & $88.0 \%$ & \\
\hline Mouth width, P1 & 808 & $6.18 \pm 0.86$ & 308 & $6.08 \pm 0.87$ & 500 & $6.24 \pm 0.85$ & .011 \\
\hline
\end{tabular}




\begin{tabular}{|c|c|c|c|c|c|c|c|}
\hline \multirow[b]{2}{*}{ Measure } & \multicolumn{2}{|c|}{ All Patients } & \multicolumn{2}{|c|}{$\begin{array}{l}\text { Control Subjects } \\
\quad(\text { AHI }<10)\end{array}$} & \multicolumn{2}{|c|}{$\begin{array}{l}\text { Subjects With OSA } \\
\quad(\mathrm{AHI} \geq 10)\end{array}$} & \multirow[b]{2}{*}{$P$} \\
\hline & No. & Estimate & No. & Estimate & No. & Estimate & \\
\hline Mouth height, $\mathrm{P} 1$ & 780 & $5.14 \pm 1.03$ & 298 & $5.10 \pm 1.08$ & 482 & $5.16 \pm 1.01$ & .377 \\
\hline Mouth area, P1 & 786 & $24.0 \pm 7.0$ & 301 & $23.3 \pm 7.5$ & 485 & $24.4 \pm 6.6$ & .025 \\
\hline Tongue width, $\mathrm{P} 1$ & 742 & $5.13 \pm 0.56$ & 290 & $5.00 \pm 0.53$ & 452 & $5.21 \pm 0.57$ & $<.0001$ \\
\hline Standard Mallampati score, P2 & & & & & & & .002 \\
\hline Class I & 26 & $3.6 \%$ & 14 & $5.2 \%$ & 12 & $2.6 \%$ & \\
\hline Class II & 72 & $9.9 \%$ & 38 & $14.1 \%$ & 34 & $7.4 \%$ & \\
\hline Class III & 201 & $27.6 \%$ & 78 & $29.0 \%$ & 123 & $26.7 \%$ & \\
\hline Class IV & 430 & $59.0 \%$ & 139 & $51.7 \%$ & 291 & $63.3 \%$ & \\
\hline Mouth width, P2 & 725 & $6.02 \pm 0.77$ & 282 & $5.94 \pm 0.81$ & 443 & $6.07 \pm 0.75$ & .027 \\
\hline Tongue width, $\mathrm{P} 2$ & 798 & $5.23 \pm 0.73$ & 306 & $5.10 \pm 0.71$ & 492 & $5.30 \pm 0.73$ & .0001 \\
\hline Tongue length, P2 & 740 & $5.82 \pm 1.23$ & 277 & $5.84 \pm 1.21$ & 463 & $5.80 \pm 1.25$ & .711 \\
\hline Tongue area, P2 & 750 & $25.9 \pm 7.9$ & 281 & $25.3 \pm 7.7$ & 469 & $26.3 \pm 8.1$ & .110 \\
\hline Tongue length, P3 & 624 & $4.30 \pm 0.81$ & 245 & $4.28 \pm 0.81$ & 379 & $4.31 \pm 0.82$ & .574 \\
\hline Tongue area, P3 & 622 & $5.54 \pm 1.94$ & 243 & $5.37 \pm 1.96$ & 379 & $5.65 \pm 1.93$ & .085 \\
\hline Tongue thickness, P3 & 626 & $1.47 \pm 0.30$ & 246 & $1.41 \pm 0.31$ & 380 & $1.51 \pm 0.28$ & $<.0001$ \\
\hline Tongue curvature, P3 & 615 & $5.31 \pm 1.25$ & 242 & $5.33 \pm 1.32$ & 373 & $5.29 \pm 1.20$ & .671 \\
\hline Airway width, P4 & 148 & $2.17 \pm 0.65$ & 88 & $2.19 \pm 0.61$ & 60 & $2.14 \pm 0.71$ & .687 \\
\hline Uvula length (airway), P4 & 169 & $0.57 \pm 0.28$ & 91 & $0.56 \pm 0.25$ & 78 & $0.59 \pm 0.31$ & .455 \\
\hline Uvula width (airway), P4 & 358 & $0.89 \pm 0.20$ & 165 & $0.86 \pm 0.18$ & 193 & $0.90 \pm 0.22$ & .057 \\
\hline Uvula area (airway), P4 & 166 & $0.38 \pm 0.22$ & 89 & $0.35 \pm 0.18$ & 77 & $0.41 \pm 0.25$ & .082 \\
\hline Global Mallampati score & & & & & & & .001 \\
\hline Class I & 17 & $2.1 \%$ & 10 & $3.3 \%$ & 7 & $1.4 \%$ & \\
\hline Class II & 70 & $8.6 \%$ & 36 & $11.9 \%$ & 34 & $6.7 \%$ & \\
\hline Class III & 174 & $21.5 \%$ & 75 & $24.7 \%$ & 99 & $19.5 \%$ & \\
\hline Class IV & 549 & $67.8 \%$ & 182 & $60.1 \%$ & 367 & $72.4 \%$ & \\
\hline Tongue ridging & & & & & & & .721 \\
\hline Absent & 209 & $25.8 \%$ & 75 & $25.1 \%$ & 134 & $26.2 \%$ & \\
\hline Evident & 601 & $74.2 \%$ & 224 & $74.9 \%$ & 377 & $73.8 \%$ & \\
\hline Tonsil hypertrophy & & & & & & & .073 \\
\hline Grade 0 & 106 & $31.6 \%$ & 56 & $35.9 \%$ & 50 & $27.8 \%$ & \\
\hline Grade 1 & 91 & $27.1 \%$ & 47 & $30.1 \%$ & 44 & $24.4 \%$ & \\
\hline Grade 2 & 74 & $22.0 \%$ & 30 & $19.2 \%$ & 44 & $24.4 \%$ & \\
\hline Grades 3 and 4 & 65 & $19.3 \%$ & 23 & $14.7 \%$ & 42 & $23.3 \%$ & \\
\hline Pharyngeal narrowing & & & & & & & .001 \\
\hline Grade 0 & 37 & $8.7 \%$ & 20 & $10.5 \%$ & 17 & $7.3 \%$ & \\
\hline Grade 1 & 156 & $36.9 \%$ & 84 & $44.2 \%$ & 72 & $30.9 \%$ & \\
\hline Grade 2 & 172 & $40.7 \%$ & 71 & $37.4 \%$ & 101 & $43.3 \%$ & \\
\hline Grade 3 & 58 & $13.7 \%$ & 15 & $7.9 \%$ & 43 & $18.5 \%$ & \\
\hline
\end{tabular}

Data are presented as mean \pm SD unless otherwise indicated. $P$ values for differences in photograph $(P)$ measures significant after Hochberg correction are shown in bold.

subjects $(89.3 \%$ vs $93.6 \% ; P=.042)$. Obtaining measurements of airway width or uvula size was more difficult due to lack of visibility, and measures were less likely to be obtained in subjects with OSA (12.6\%$40.6 \%)$ compared with control subjects (29.7\%-55.7\%). Results for these measures should be interpreted 
cautiously given their availability on a subset of the population (specifically, younger, less obese subjects who are less likely to have apnea). This outcome is also true for global measures of tonsil hypertrophy and pharyngeal narrowing.

\section{Subject Demographic Characteristics}

The study sample consisted of 542 subjects with OSA and 318 control subjects. Subjects with OSA were older, heavier, more likely to be male, and more likely to be African American (Table 3). Given these differences, statistical models were used to control for these variables; there was a reasonable overlap in age and BMI between subjects with OSA and control subjects to allow for statistical adjustment (e-Fig 1).

\section{Associations Between Photography Measurements and OSA Status}

In unadjusted comparisons of means and frequencies between subjects with OSA and control subjects (Table 3), nominally $(P<.05)$ or statistically (after Hochberg correction) significant differences for a number of photography-derived measures were recorded. Subjects with apnea had higher scores on all measures of Mallampati, less airway visibility, larger mouth width and area, and larger tongue width and thickness. These subjects also had more severe pharyngeal narrowing within the subpopulation where this measure was quantifiable.

We next examined the relationship between photograph variables and the likelihood of OSA (Table 4). In unadjusted models in photograph $\mathrm{P} 1$, larger tongue width was significantly associated with increased odds of OSA, whereas larger mouth width, mouth area, and a nonvisible airway were nominally associated. Similarly, a higher modified Mallampati score was nominally associated with OSA risk; subjects in Class IV had a 2.65 times increased odds of OSA compared with subjects in Class I. In photograph P2, larger tongue width and a higher standard Mallampati score were significantly associated with OSA risk, and mouth width was nominally associated. When examining the size of the tongue in the profile tongue-extended photograph (P3), a $1 \mathrm{SD}$ increase in tongue thickness was significantly

TABLE 4 ] Associations Between Photographic Measures and OSA Status

\begin{tabular}{|c|c|c|c|c|c|c|}
\hline \multirow[b]{2}{*}{ Measure } & \multicolumn{2}{|c|}{ Unadjusted } & \multicolumn{2}{|c|}{ Age-, Sex-, and Race-Adjusted } & \multicolumn{2}{|c|}{$\begin{array}{l}\text { Age-, Sex-, Race-, and } \\
\text { BMI-Adjusted }\end{array}$} \\
\hline & Estimate $^{a}$ & $P$ & Estimate $^{a}$ & $P$ & Estimate $^{a}$ & $P$ \\
\hline \multicolumn{7}{|l|}{ Photograph P1 } \\
\hline Modified Mallampati score & Overall & .022 & Overall & .120 & Overall & .213 \\
\hline Class I & 1.00 (ref) & $\ldots$ & 1.00 (ref) & $\ldots$ & 1.00 (ref) & $\ldots$ \\
\hline Class II & $1.76(0.79-3.94)$ & .166 & $1.92(0.82-4.53)$ & .134 & $2.24(0.88-5.66)$ & .089 \\
\hline Class III & $2.27(1.06-4.85)$ & .035 & $2.45(1.09-5.49)$ & .029 & $2.51(1.05-6.02)$ & .039 \\
\hline Class IV & $2.65(1.33-5.30)$ & .006 & $2.36(1.13-4.93)$ & .022 & $2.27(1.02-5.02)$ & .044 \\
\hline Airway not visible & $1.74(1.16-2.59)$ & .007 & $1.52(0.99-2.34)$ & .057 & $1.33(0.83-2.12)$ & .233 \\
\hline Mouth width & $1.21(1.04-1.39)$ & .011 & $1.15(0.98-1.35)$ & .095 & $1.03(0.86-1.22)$ & .766 \\
\hline Mouth height & $1.07(0.92-1.24)$ & .369 & $1.02(0.87-1.19)$ & .817 & $0.97(0.81-1.14)$ & .687 \\
\hline Mouth area & $1.19(1.03-1.38)$ & .022 & $1.15(0.98-1.35)$ & .087 & $1.04(0.88-1.24)$ & .644 \\
\hline Tongue width & $1.46(1.25-1.71)$ & $<.0001$ & $1.33(1.12-1.58)$ & .001 & $1.10(0.91-1.32)$ & .347 \\
\hline \multicolumn{7}{|l|}{ Photograph P2 } \\
\hline Standard Mallampati score & Overall & .002 & Overall & .099 & Overall & .375 \\
\hline Class I & 1.00 (ref) & $\ldots$ & 1.00 (ref) & $\ldots$ & 1.00 (ref) & $\ldots$ \\
\hline Class II & $1.04(0.42-2.57)$ & .926 & $1.80(0.68-4.79)$ & .240 & $1.44(0.50-4.20)$ & .500 \\
\hline Class III & $1.84(0.81-4.18)$ & .146 & $2.38(0.98-5.77)$ & .055 & $1.94(0.75-5.07)$ & .173 \\
\hline Class IV & $2.44(1.10-5.42)$ & .028 & $2.64(1.12-6.24)$ & .027 & $2.01(0.79-5.10)$ & .142 \\
\hline Mouth width & $1.19(1.02-1.38)$ & .025 & $1.11(0.94-1.32)$ & .218 & $1.04(0.87-1.25)$ & .642 \\
\hline Tongue width & $1.33(1.15-1.54)$ & $<.001$ & $1.26(1.07-1.48)$ & .006 & $1.09(0.91-1.31)$ & .324 \\
\hline Tongue length & $0.97(0.84-1.13)$ & .713 & $0.97(0.82-1.13)$ & .673 & $0.85(0.71-1.01)$ & .067 \\
\hline Tongue area & $1.13(0.97-1.31)$ & .114 & $1.10(0.93-1.29)$ & .256 & $0.95(0.80-1.14)$ & .584 \\
\hline
\end{tabular}




\begin{tabular}{|c|c|c|c|c|c|c|}
\hline \multirow[b]{2}{*}{ Measure } & \multicolumn{2}{|c|}{ Unadjusted } & \multicolumn{2}{|c|}{ Age-, Sex-, and Race-Adjusted } & \multicolumn{2}{|c|}{$\begin{array}{l}\text { Age-, Sex-, Race-, and } \\
\text { BMI-Adjusted }\end{array}$} \\
\hline & Estimate $^{a}$ & $P$ & Estimate $^{a}$ & $P$ & Estimate $^{a}$ & $P$ \\
\hline \multicolumn{7}{|l|}{ Photograph P3 } \\
\hline Tongue length & $1.05(0.89-1.23)$ & .574 & $1.03(0.87-1.23)$ & .731 & $0.92(0.76-1.12)$ & .411 \\
\hline Tongue area & $1.15(0.98-1.36)$ & .085 & $1.09(0.92-1.30)$ & .321 & $0.97(0.80-1.17)$ & .724 \\
\hline Tongue thickness & $1.43(1.21-1.70)$ & $<.0001$ & $1.29(1.07-1.54)$ & .007 & $1.12(0.93-1.36)$ & .230 \\
\hline Tongue curvature & $0.96(0.82-1.13)$ & .664 & $0.95(0.80-1.13)$ & .594 & $0.88(0.73-1.06)$ & .167 \\
\hline \multicolumn{7}{|l|}{ Photograph P4 } \\
\hline Airway width & $0.93(0.67-1.30)$ & .675 & $0.87(0.60-1.24)$ & .436 & $0.83(0.55-1.26)$ & .378 \\
\hline Uvula length (airway) & $1.12(0.83-1.52)$ & .445 & $1.22(0.86-1.72)$ & .266 & $1.02(0.71-1.48)$ & .911 \\
\hline Uvula width (airway) & $1.22(0.99-1.51)$ & .061 & $1.04(0.82-1.32)$ & .747 & $1.10(0.85-1.43)$ & .460 \\
\hline Uvula area (airway) & $1.32(0.97-1.81)$ & .079 & $1.35(0.94-1.95)$ & .109 & $1.19(0.81-1.75)$ & .364 \\
\hline \multicolumn{7}{|l|}{ Global measures } \\
\hline Global Mallampati score & Overall & .002 & Overall & .072 & Overall & .369 \\
\hline Class I & 1.00 (ref) & $\ldots$ & 1.00 (ref) & $\ldots$ & 1.00 (ref) & $\ldots$ \\
\hline Class II & $1.35(0.46-3.95)$ & .584 & $1.57(0.51-4.89)$ & .434 & $1.61(0.46-5.63)$ & .452 \\
\hline Class III & $1.89(0.69-5.18)$ & .219 & $1.94(0.67-5.62)$ & .224 & $1.66(0.52-5.36)$ & .394 \\
\hline Class IV & $2.88(1.08-7.69)$ & .035 & $2.56(0.91-7.19)$ & .075 & $2.11(0.68-6.56)$ & .199 \\
\hline Evident tongue ridging & $0.94(0.68-1.31)$ & .721 & $1.03(0.73-1.46)$ & .854 & $1.15(0.79-1.68)$ & .458 \\
\hline Tonsil hypertrophy & Overall & .076 & Overall & .012 & Overall & .034 \\
\hline Grade 0 & 1.00 (ref) & $\ldots$ & 1.00 (ref) & $\ldots$ & 1.00 (ref) & $\ldots$ \\
\hline Grade 1 & $1.05(0.60-1.84)$ & .869 & $1.58(0.84-2.96)$ & .153 & $1.63(0.83-3.23)$ & .158 \\
\hline Grade 2 & $1.64(0.90-3.00)$ & .105 & $2.47(1.26-4.84)$ & .008 & $2.74(1.31-5.74)$ & .008 \\
\hline Grades 3 and 4 & $2.05(1.08-3.86)$ & .027 & $2.99(1.42-6.29)$ & .004 & $2.45(1.11-5.44)$ & .027 \\
\hline Pharyngeal narrowing & Overall & .002 & Overall & .002 & Overall & .073 \\
\hline Grade 0 & 1.00 (ref) & $\ldots$ & 1.00 (ref) & $\ldots$ & 1.00 (ref) & $\ldots$ \\
\hline Grade 1 & $1.01(0.49-2.07)$ & .982 & $1.33(0.62-2.86)$ & .467 & $1.43(0.63-3.26)$ & .393 \\
\hline Grade 2 & $1.67(0.82-3.42)$ & .158 & $2.33(1.08-5.03)$ & .032 & $2.11(0.92-4.82)$ & .076 \\
\hline Grade 3 & $3.37(1.41-8.08)$ & .006 & $4.10(1.61-10.47)$ & .003 & $3.03(1.13-8.14)$ & .028 \\
\hline
\end{tabular}

$P$ values for differences in photograph measures significant after Hochberg correction are shown in bold.

aEstimates presented as OR (95\% CI) from logistic regression models (unadjusted or controlling for indicated covariates) for OSA associated with a 1 SD increase in continuous measures or compared with the indicated reference category for categorical measures.

associated with a 1.43 times increased odds of OSA. Significant associations were also seen in global categorical measures, with a more severe Mallampati score and worse pharyngeal narrowing associated with a higher likelihood of OSA. Subjects with a pharyngeal narrowing grade of 3 had a 3.37 times increased odds of OSA compared with subjects with a grade of 0 . None of the airway or uvula measures in photograph $\mathrm{P} 4$ showed significant associations in the subset with available data.

Table 4 also illustrates covariate-adjusted associations with OSA status. In partially adjusted models controlling for age, sex, and race, larger tongue width remained significantly associated with increased OSA risk (after Hochberg correction), whereas tongue thickness, pharyngeal narrowing, and more severe tonsil grade remained or became nominally significant. After additional adjustment for BMI, only tonsil hypertrophy grade remained nominally associated.

\section{Associations Between Photography Measurements and $\mathrm{AHI}$}

We next examined associations between photographic measures and continuous AHI (Table 5). In unadjusted models for photograph P1, larger mouth width, tongue width, a nonvisible airway, and higher modified Mallampati score were significantly associated with higher AHI; larger mouth area showed nominal 
TABLE 5 ] Associations Between Photographic Measures and $\ln (\mathrm{AHI}+1)$

\begin{tabular}{|c|c|c|c|c|c|c|}
\hline \multirow[b]{2}{*}{ Measure } & \multicolumn{2}{|c|}{ Unadjusted } & \multicolumn{2}{|c|}{ Age-, Sex-, and Race-Adjusted } & \multicolumn{2}{|c|}{ Age-, Sex-, Race-, and BMI-Adjusted } \\
\hline & Estimate $^{a}$ & $P$ & Estimate $^{a}$ & $P$ & Estimate $^{a}$ & $P$ \\
\hline \multicolumn{7}{|l|}{ Photograph P1 } \\
\hline Modified Mallampati score & Overall & .0001 & Overall & .002 & Overall & .015 \\
\hline Class I & 0.00 (ref) & $\ldots$ & 0.00 (ref) & $\ldots$ & 0.00 (ref) & $\ldots$ \\
\hline Class II & $0.40(-0.06$ to 0.86$)$ & .085 & $0.38(-0.05$ to 0.81$)$ & .083 & $0.38(0.00$ to 0.76$)$ & .049 \\
\hline Class III & $0.54(0.11$ to 0.97$)$ & .014 & $0.52(0.12$ to 0.92$)$ & .011 & $0.42(0.06$ to 0.78$)$ & .021 \\
\hline Class IV & $0.77(0.38$ to 1.16$)$ & $<.001$ & $0.65(0.28$ to 1.02$)$ & .001 & $0.51(0.19$ to 0.84$)$ & .002 \\
\hline Airway not visible & $0.45(0.22$ to 0.68$)$ & $<.001$ & $0.37(0.15$ to 0.58$)$ & .001 & $0.23(0.04$ to 0.43$)$ & .018 \\
\hline Mouth width & $0.13(0.05$ to 0.21$)$ & .001 & $0.08(-0.01$ to 0.16$)$ & .067 & $0.01(-0.06$ to 0.08$)$ & .799 \\
\hline Mouth height & $0.04(-0.04$ to 0.12$)$ & .320 & $0.00(-0.08$ to 0.08$)$ & .946 & $-0.03(-0.09$ to 0.04$)$ & .478 \\
\hline Mouth area & $0.10(0.02$ to 0.18$)$ & .016 & $0.06(-0.03$ to 0.14$)$ & .179 & $-0.00(-0.08$ to 0.07$)$ & .915 \\
\hline Tongue width & $0.25(0.17$ to 0.34$)$ & $<.0001$ & $0.17(0.09$ to 0.26$)$ & $<.001$ & $0.05(-0.03$ to 0.12$)$ & .218 \\
\hline \multicolumn{7}{|l|}{ Photograph P2 } \\
\hline $\begin{array}{l}\text { Standard Mallampati } \\
\text { score }\end{array}$ & Overall & $<.0001$ & Overall & .002 & Overall & .035 \\
\hline Class I & 0.00 (ref) & $\cdots$ & 0.00 (ref) & $\ldots$ & 0.00 (ref) & $\ldots$ \\
\hline Class II & $0.04(-0.47$ to 0.56$)$ & .868 & $0.34(-0.16$ to 0.84$)$ & .183 & $0.19(-0.25$ to 0.64$)$ & .395 \\
\hline Class III & $0.48(0.01$ to 0.95$)$ & .047 & $0.58(0.13$ to 1.04$)$ & .011 & $0.40(-0.00$ to 0.80$)$ & .053 \\
\hline Class IV & $0.72(0.26$ to 1.18$)$ & .002 & $0.71(0.27$ to 1.15$)$ & .002 & $0.46(0.06$ to 0.85$)$ & .023 \\
\hline Mouth width & $0.12(0.03$ to 0.21$)$ & .007 & $0.06(-0.02$ to 0.15$)$ & .159 & $0.02(-0.06$ to 0.09$)$ & .655 \\
\hline Tongue width & $0.20(0.12$ to 0.29$)$ & $<.0001$ & $0.16(0.08$ to 0.24$)$ & $<.001$ & $0.06(-0.01$ to 0.13$)$ & .102 \\
\hline Tongue length & $0.01(-0.07$ to 0.10$)$ & .806 & $0.01(-0.08$ to 0.09$)$ & .895 & $-0.06(-0.13$ to 0.02$)$ & .130 \\
\hline Tongue area & $0.10(0.01$ to 0.18$)$ & .027 & $0.07(-0.01$ to 0.15$)$ & .097 & $-0.01(-0.08$ to 0.06$)$ & .757 \\
\hline \multicolumn{7}{|l|}{ Photograph P3 } \\
\hline Tongue length & $0.04(-0.06$ to 0.13$)$ & .447 & $0.02(-0.06$ to 0.11$)$ & .603 & $-0.04(-0.12$ to 0.04$)$ & .335 \\
\hline Tongue area & $0.09(-0.00$ to 0.18$)$ & .053 & $0.04(-0.04$ to 0.13$)$ & .319 & $-0.03(-0.11$ to 0.05$)$ & .416 \\
\hline Tongue thickness & $0.24(0.15$ to 0.33$)$ & $<.0001$ & $0.15(0.06$ to 0.24$)$ & .001 & $0.06(-0.02$ to 0.14$)$ & .153 \\
\hline Tongue curvature & $-0.01(-0.10$ to 0.08$)$ & .817 & $-0.01(-0.10$ to 0.08$)$ & .801 & $-0.05(-0.13$ to 0.02$)$ & .178 \\
\hline \multicolumn{7}{|l|}{ Photograph P4 } \\
\hline Airway width & $0.01(-0.18$ to 0.20$)$ & .908 & $-0.03(-0.20$ to 0.14$)$ & .739 & $-0.02(-0.17$ to 0.12$)$ & .780 \\
\hline Uvula length (airway) & $0.09(-0.08$ to 0.26$)$ & .308 & $0.11(-0.05$ to 0.26$)$ & .174 & $0.04(-0.10$ to 0.17$)$ & .606 \\
\hline
\end{tabular}


TABLE 5 ] (Continued)

\begin{tabular}{|c|c|c|c|c|c|c|}
\hline \multirow[b]{2}{*}{ Measure } & \multicolumn{2}{|c|}{ Unadjusted } & \multicolumn{2}{|c|}{ Age-, Sex-, and Race-Adjusted } & \multicolumn{2}{|c|}{ Age-, Sex-, Race-, and BMI-Adjusted } \\
\hline & Estimate $^{a}$ & $P$ & Estimate $^{a}$ & $P$ & Estimate $^{a}$ & $P$ \\
\hline Uvula width (airway) & $0.14(0.02$ to 0.25$)$ & .021 & $0.01(-0.11$ to 0.12$)$ & .926 & $0.03(-0.07$ to 0.12$)$ & .588 \\
\hline Uvula area (airway) & $0.17(-0.00$ to 0.34$)$ & .054 & $0.12(-0.03$ to 0.28$)$ & .124 & $0.07(-0.07$ to 0.21$)$ & .319 \\
\hline Global Mallampati score & Overall & $<.0001$ & Overall & .001 & Overall & .034 \\
\hline Class I & 0.00 (ref) & $\ldots$ & $0.00($ ref $)$ & & 0.00 (ref) & \\
\hline Class II & $0.20(-0.41$ to 0.81$)$ & .525 & $0.23(-0.35$ to 0.81$)$ & .437 & $0.17(-0.34$ to 0.68$)$ & .521 \\
\hline Evident tongue ridging & $-0.09(-0.27$ to 0.09$)$ & .345 & $-0.04(-0.21$ to 0.14$)$ & .693 & $0.04(-0.12$ to 0.19$)$ & .656 \\
\hline Tonsil hypertrophy & Overall & .005 & Overall & .0001 & Overall & .001 \\
\hline Grade 0 & 0.00 (ref) & $\ldots$ & 0.00 (ref) & $\ldots$ & 0.00 (ref) & $\ldots$ \\
\hline Grade 1 & $-0.07(-0.39$ to 0.26$)$ & .683 & $0.19(-0.10$ to 0.49$)$ & 204 & $0.14(-0.12$ to 0.40$)$ & .280 \\
\hline Grade 2 & $0.30(-0.04$ to 0.64$)$ & .088 & $0.52(0.20$ to 0.83$)$ & .001 & $0.43(0.16$ to 0.71$)$ & .002 \\
\hline Grade 2 & $0.30(-0.11$ to 0.71$)$ & .155 & $0.45(0.06$ to 0.84$)$ & .023 & $0.32(-0.02$ to 0.67$)$ & .065 \\
\hline Grade 3 & $0.97(0.49$ to 1.45$)$ & $<.001$ & $1.02(0.57$ to 1.47$)$ & $<.0001$ & $0.77(0.37$ to 1.18$)$ & $<.001$ \\
\hline
\end{tabular}

$P$ values for differences in photograph measures significant after Hochberg correction are shown in bold.

aEstimates presented as estimated mean change (95\% CI) in In(AHI+1) (natural log) from linear regression models (unadjusted or controlling for indicated covariates) associated with a 1 SD increase in continuous

measures or compared with the indicated reference category for categorical measures. 
significance. Airway visibility, modified Mallampati score, and tongue width remained statistically significant after adjusting for age, sex, and race. When including BMI, airway visibility and modified Mallampati score remained nominally significant. In photograph P2, larger mouth width, tongue width, and tongue area, as well as a higher standard Mallampati score, were all significantly or nominally associated with higher AHI. Adjusting for age, sex, and race, the standard Mallampati score and tongue width remained significantly associated; only the standard Mallampati score was nominally associated after BMI adjustment. Larger tongue thickness on photograph P3 was significantly associated with more severe AHI in the unadjusted and partially adjusted models but not after additional adjustment for BMI. Similarly, larger uvula width (P4) was nominally associated with AHI in unadjusted analyses only. For global categorical measures, more severe Mallampati score, tonsil hypertrophy grade, and pharyngeal narrowing grade were nominally or significantly associated with higher AHI values in all models.

\section{Multivariate Associations With OSA Measures}

Multivariate regression with backwards selection was used to examine whether there were independent effects among all variables from photographs $\mathrm{P} 1, \mathrm{P} 2$, and P3, which were visible in at least $89 \%$ of photographed subjects, as well as clinical factors (age, BMI, sex, and race). A total of 430 subjects had data for all measures and were included in multivariate models; there were no significant differences in age, sex, race, BMI, or AHI between included and excluded subjects.

When examining associations with OSA status, the backwards selection algorithm resulted in a final model, including sex $(P=.003)$, age $(P<.0001)$, and BMI $(P<.0001)$ as important clinical predictors, as well as significant independent associations for tongue area $(P=.008)$ and curvature $(P=.003)$ from the profile tongue-extended photograph. Thus, the results suggest that profile measures of the tongue capture unique aspects related to OSA risk.

Similarly, when examining associations with AHI, selected clinical covariates included sex $(P<.0001)$, age $(P<.0001)$, and BMI $(P<.0001)$. A number of photography-derived variables showed significant independent associations in the final model, including standard Mallampati score $(P=.028)$, tongue width $(P=.0005)$, and tongue length $(P=.022)$ from the frontal photograph with the tongue extended maximally, and tongue length $(P=.031)$ and curvature $(P=.020)$ from the profile tongue-extended photograph. Once again, these results suggest that photography variables provide additional information after accounting for clinical factors.

\section{Discussion}

This investigation confirms data from other imaging studies $^{17-23,29,32-34}$ showing associations between intraoral anatomy and OSA but using a less invasive, higher throughput, and more cost-efficient method. Previous noninvasive studies have attempted to phenotype intraoral anatomy but have been limited to primarily qualitative studies and have not quantified pharyngeal structures. ${ }^{16}$ Our validated method of digital morphometrics using a laser ruler provides an efficient and reproducible method to quantify mouth and tongue sizes, as well as airway visibility measures, in a high proportion of photographed individuals.

Using our method, we examined the relationship between intraoral measures and both AHI and OSA status in a large sample. Measurements of intraoral crowdedness showed the strongest associations. A higher Mallampati score and nonvisible airway were both risk factors for more severe OSA, even after controlling for age, sex, race, and BMI; subjects with OSA tended to have more crowded or less visible airways than control subjects. Pharyngeal airway visibility is a dichotomous analogue of the modified Mallampati score measuring pharyngeal crowding and may represent a more efficient first-stage screening tool for identifying subjects with increased OSA risk. This relationship between increased apnea severity and intraoral crowdedness was also reflected in associations with AHI for both tonsil hypertrophy and pharyngeal narrowing grade, within a subset of the population.

Mouth width and area were also associated with OSA status, although significance was lost after full covariate adjustment. A small lateral mouth opening will contribute to decreased pharyngeal airway visibility and increased modified Mallampati score. Similarly, larger tongue width and tongue thickness were associated with increased likelihood of OSA and higher AHI.

Associations remained significant when controlling for age, sex, and race but were lost after adjustment for BMI. Because BMI is related to tongue size and tongue fat, ${ }^{7,35}$ it is not surprising that statistical significance was lost. However, measures of tongue size and morphology could provide additional insights into appropriate treatment approaches that are not obvious based on 
BMI alone. Supporting the idea that photography measures of the tongue may capture unique aspects of OSA risk, several measures of the tongue showed significant associations $(P<.05)$ in multivariate analyses, even in the presence of age, sex, and BMI. These associations, as well as possible interactions among variables, should be examined within independent datasets.

\section{Limitations and Strengths}

The study's limitations and strengths are discussed in e-Appendix 1.

\section{Utility of Digital Morphometrics}

The overall potential of our digital morphometric analysis paradigm may be its ability to predict or model the likelihood of developing OSA based on airway pharyngeal visibility and tongue size. Photography could be used to determine anatomic risk factors for OSA in large population studies or screening studies.

Obtaining and storing photographs also allows for future assessments of intraoral structures. This approach is not possible if, for example, a study is recording the Mallampati score based only on visual inspection of the airway. Thus, digital morphometrics may provide a more reproducible and standardized objective measurement technique for capturing the Mallampati score, which may provide clinical benefit. Although the size of intraoral structures has been shown to be predictive of OSA, ${ }^{16}$ most large trials and cohorts evaluating patients with sleep apnea have not assessed upper airway anatomy, instead relying on clinical measures of overall obesity. OSA is one of the few diseases in which detailed physical examination is largely ignored.

Digital morphometrics represent an efficient and costeffective method of examining intraoral crowding and tongue size for large population genetic studies and/or examination of differences across ethnicity; the process can be expanded to include craniofacial structures as described previously. ${ }^{23}$ Combining the intraoral digital morphometric analyses described here with craniofacial assessments allows for comprehensive phenotyping of OSA risk factors. Future studies should examine sensitivity and specificity for predicting OSA using individual or combinations of photographically derived phenotypes. Moreover, digital morphometrics could be used to efficiently observe subjects through weight loss and address relationships between BMI, AHI, and tongue size. As the relationships between intraoral structures and apnea are documented, digital morphometrics could be used to help identify optimal, personalized OSA interventions.

\section{Conclusions}

We showed that a digital camera and laser ruler can be used to quantify intraoral anatomy, particularly for measures of the tongue and mouth, airway visibility, and Mallampati score. Using the techniques described, we obtained reproducible measures of a number of OSArelated anatomic risk factors in a large proportion of photographed subjects. Measures of tongue size were associated with increased OSA risk and higher AHI, independent of age, sex, and race. Categorical measures of airway visibility and modified Mallampati score showed associations with $\mathrm{AHI}$, independent of BMI, age, sex, and race and differed between subjects with OSA and control subjects. Multivariate modeling suggests that photographic measures capture unique aspects of OSA risk and severity. Thus, our photography techniques represent a promising tool for highthroughput, cost-effective intraoral phenotyping or OSA screening, which until now has required more expensive imaging. 


\section{Acknowledgments}

Author contributions: R. J. S. is the guarantor of the study. R. J. S., C. B. B., and R. B. R. were responsible for conception and design. S. E. L., C. B. B., R. B. R., A. N., and $S$. W. were responsible for data acquisition. S. E. L., C. B. B., R. B. R., A. N., S. W., G. M., B. T. K., and R. J. S. were responsible for analysis and interpretation. R. J. S., S. E. L., and B. T. K. drafted the manuscript. R. J. S., S. E. L., and B. T. K. conducted critical revisions. All authors gave final approval of the version to be published.

Financial/nonfinancial disclosures: None declared.

Role of sponsors: The sponsor had no role in the design of the study, the collection and analysis of the data, or the preparation of the manuscript.

Other contributions: The authors thank Branden Stearns, $\mathrm{ScB}$, for his contributions to this article.

Additional information: The e-Appendix, e-Figure, and e-Tables can be found in the Supplemental Materials section of the online article.

\section{References}

1. Peppard PE, Young T, Barnet JH, Palta M, Hagen EW, Hla KM. Increased prevalence of sleep-disordered breathing in adults. Am J Epidemiol. 2013;177(9):1006-1014.

2. Tufik S, Santos-Silva R, Taddei JA, Bittencourt LR. Obstructive sleep apnea syndrome in the Sao Paulo Epidemiologic Sleep Study. Sleep Med. 2010;11(5): 441-446.

3. Punjabi NM. The epidemiology of adult obstructive sleep apnea. Proc Am Thorac Soc. 2008;5(2):136-143.

4. Young T, Skatrud J, Peppard PE. Risk factors for obstructive sleep apnea in adults. JAMA. 2004;291(16):2013-2016.

5. Wolk R, Shamsuzzaman AS, Somers VK. Obesity, sleep apnea, and hypertension. Hypertension. 2003;42(6):1067-1074.

6. Foster GD, Borradaile KE, Sanders MH, et al; Sleep AHEAD Research Group of Look AHEAD Research Group. A randomized study on the effect of weight loss on obstructive sleep apnea among obese patients with type 2 diabetes: the Sleep AHEAD study. Arch Intern Med. 2009;169(17):1619-1626.

7. Kim AM, Keenan BT, Jackson N, et al. Tongue fat and its relationship to obstructive sleep apnea. Sleep. 2014;37(10):1639-1648.

8. Cuccia AM, Campisi G, Cannavale R, Colella G. Obesity and craniofacial variables in subjects with obstructive sleep apnea syndrome: comparisons of cephalometric values. Head Face Med. 2007;3:41.
9. Schwab RJ, Pasirstein M, Pierson R, et al. Identification of upper airway anatomic risk factors for obstructive sleep apnea with volumetric magnetic resonance imaging. Am J Respir Crit Care Med. 2003;168(5):522-530.

10. Chi L, Comyn FL, Mitra N, et al. Identification of craniofacial risk factors for obstructive sleep apnoea using threedimensional MRI. Eur Respir J. 2011;38(2):348-358.

11. Lee RW, Vasudavan S, Hui DS, et al. Differences in craniofacial structures and obesity in Caucasian and Chinese patients with obstructive sleep apnea. Sleep. 2010;33(8):1075-1080.

12. Ciscar MA, Juan G, Martinez V, et al. Magnetic resonance imaging of the pharynx in OSA patients and healthy subjects. Eur Respir J. 2001;17(1):79-86.

13. Sutherland K, Lee RW, Cistulli PA. Obesity and craniofacial structure as risk factors for obstructive sleep apnoea: impact of ethnicity. Respirology. 2012;17(2):213-222

14. Vos W, De Backer J, Devolder A, et al. Correlation between severity of sleep apnea and upper airway morphology based on advanced anatomical and functional imaging. $J$ Biomech. 2007;40(10):2207-2213.

15. Schwab RJ, Pasirstein M, Kaplan L, et al. Family aggregation of upper airway soft tissue structures in normal subjects and patients with sleep apnea. Am J Respir Crit Care Med. 2006;173(4):453-463.

16. Schellenberg JB, Maislin G, Schwab RJ. Physical findings and the risk for obstructive sleep apnea. The importance of oropharyngeal structures. Am J Respir Crit Care Med. 2000;162(2 pt 1):740-748.

17. Tsai WH, Remmers JE, Brant R, Flemons WW, Davies J, Macarthur C. A decision rule for diagnostic testing in obstructive sleep apnea. Am J Respir Crit Care Med. 2003;167(10):1427-1432.

18. Friedman M, Tanyeri H, La Rosa M, et al. Clinical predictors of obstructive sleep apnea. Laryngoscope. 1999;109(12): 1901-1907.

19. Hukins C. Mallampati class is not useful in the clinical assessment of sleep clinic patients. J Clin Sleep Med. 2010;6(6): 545-549.

20. Mallampati SR. Clinical sign to predict difficult tracheal intubation (hypothesis). Can Anaesth Soc J. 1983;30(3 pt 1): 316-317.

21. Kushida CA, Efron B, Guilleminault C. A predictive morphometric model for the obstructive sleep apnea syndrome. Ann Intern Med. 1997;127(8 pt 1):581-587.

22. Cakirer B, Hans MG, Graham G, Aylor J, Tishler PV, Redline S. The relationship between craniofacial morphology and obstructive sleep apnea in whites and in
African-Americans. Am J Respir Crit Care Med. 2001;163(4):947-950.

23. Lee RW, Chan AS, Grunstein RR, Cistulli PA. Craniofacial phenotyping in obstructive sleep apnea-a novel quantitative photographic approach. Sleep. 2009;32(1):37-45.

24. Cary BB, Ramya B, Eugenia LC, Richard JS. Differences in upper airway anatomy between apneics and controls using digital morphometrics. Am J Respir Crit Care Med. 2012;185:A3601.

25. Cary BB, Francois-Louis C, Richard JS. Craniofacial and intraoral anatomical differences between obese white and black Americans as measured with digital morphometrics. Am J Respir Crit Care Med. 2013;187:A5938.

26. Cary BB, Nicholas J, Christopher K, Greg M, Richard JS. A novel photographic technique to relate an increase in tongue size to an increase in apnea-hypopnea index for obese apneics. Am J Respir Crit Care Med. 2012;183:A3679.

27. Cary BB, Christopher K, Thorarinn G, et al. Photographic measures of the tongue and upper airway correlate to anatomical measures taken from magnetic resonance images. Am J Respir Crit Care Med. 2012;185:A3604.

28. Kim AM, Keenan BT, Jackson N, et al Metabolic activity of the tongue in obstructive sleep apnea. A novel application of FDG positron emission tomography imaging. Am J Respir Crit Care Med. 2014;189(11):1416-1425.

29. Barbera AL, Sampson WJ, Townsend GC An evaluation of head position and craniofacial reference line variation. Homo. 2009;60(1):1-28.

30. Hochberg Y. A sharper Bonferroni procedure for multiple tests of significance. Biometrika. 1988;75(4): 800-802.

31. Huang Y, Hsu JC. Hochberg's step-up method: cutting corners off Holm's stepdown method. Biometrika. 2007;94(4): 965-975.

32. Weiss TM, Atanasov S, Calhoun KH. The association of tongue scalloping with obstructive sleep apnea and related sleep pathology. Otolaryngol Head Neck Surg. 2005;133(6):966-971.

33. Friedman M, Ibrahim H, Joseph NJ. Staging of obstructive sleep apnea/ hypopnea syndrome: a guide to appropriate treatment. Laryngoscope. 2004;114(3):454-459.

34. Brodsky L. Modern assessment of tonsils and adenoids. Pediatr Clin North Am. 1989;36(6):1551-1569.

35. Nashi N, Kang S, Barkdull GC, Lucas J, Davidson TM. Lingual fat at autopsy. Laryngoscope. 2007;117(8): 1467-1473. 